\title{
Project Risk Management Incorporating Knight, Ellsberg \& Kahneman
}

\author{
John Prpić \\ Faculty of Business Administration, Technology and Social Sciences \\ Lulea University of Technology
}

\begin{abstract}
This work investigates the Practice Standard for Project Risk Management (PSPRM) in light of the fundamental organizational risk research. As a result of this investigation, the work finds that the PSPRM is lacking some key concepts from the extant organizational risk literature and that other fundamental risk concepts are not applied in a manner consistent with the literature. Building on these findings, the work illustrates how project risk management and project risk research might be effected by these deficiencies and recommends some simple measures that could be implemented to usefully augment the PSPRM and project risk research.
\end{abstract}

\section{Introduction ${ }^{1}$}

Risk management, particularly in relation to budget and schedule overruns, is central to the management of projects. Due to the importance of this aspect of projects, project risk management has been established as one of the nine knowledge areas of the PMBOK guide. The relative importance of risk management for projects is further illustrated through a separate credential issued by the PMI for project risk management, known as the PMI-RMP ${ }^{2}$. The PMI-RMP stems from a separate guide to benchmark risk practice in projects known as 'The Practice Standard for Project Risk Management'3 (PSPRM), and the credential has been created as a response to project management's increasing growth, complexity and diversity ${ }^{4}$.

Due to the special characteristics of projects 5 , the unique challenges faced by project managers in project work, and the increasing prominence and importance of projects in the business environment, this article aims to evaluate whether the PSPRM

\footnotetext{
${ }^{1}$ Special thanks to Matti Rossi, Manuel Wiesche, Blaize Reich, Vern Bachor, Stelvia Matos, and Jeremy Hall for useful feedback on earlier incarnations of this work.

$2_{\text {http://www.pmi.org/certification/pmi-risk-management-professional-pmi-rmp.aspx }}$

http://marketplace.pmi.org/Pages/ProductDetail.aspx?GMProduct=00101169201

thttp://www.pmi.org/en/Certification/PMI-Risk-Management-Professional-PMI-RMP.asp
}

represents risk management in-line with the fundamental tenets of the organizational risk research. Although other researchers have discussed the shortcomings of risk management in projects [1, $2,3]$, these works have not specifically focused on the PSPRM, instead they have focused on specific aspects of the risk management process, such as risk identification. The focus of this research is on the PSPRM specifically, and the entire PSPRM risk management process taken holistically. Such a holistic view is of particular interest and importance to project managers practicing the PSPRM process, given that they undertake the complete PSPRM process during a project, and project risk management researchers who may predicate their efforts on particular aspects of the framework $[4,5]$.

In the following sections of this work, these goals will be achieved by first providing a review of the extant organizational risk literature, with a focus on the foundational works of Knight, Ellsberg, and Kahneman, followed by a detailed review of the PSPRM. The inconsistencies and gaps between the research and the PSPRM are discussed, and specific areas that have particular importance for project risk management practice and research are illustrated. Building on this analysis some simple measures are introduced that could be implemented to improve the PSPRM to bring it in-line with the fundamental tenets of the organizational risk literature. From here, the limitations of the work are discussed, therein outlining some interesting directions for future research, before concluding with a brief summary of the major findings of the research.

\section{Organizational Risk}

In this section the development of Business risk thought is traced from its beginnings in the

\footnotetext{
${ }^{5}$ I use the term project or projects as an umbrella term encompassing IS projects too. As discussed later in this work, the PSPRM is used to train and credential IT Project Managers, and thus is of material importance to both IT practitioners and IS risk researchers.
} 
economics literature to its use in organizational theory in the present day.

\subsection{Risk and Uncertainty}

The modern idea of risk-thinking begins almost a century ago with the work of Economist Frank Knight [6]. In his influential work, 'Risk, Uncertainty and Profit', Knight frames the central problem of business as:
"It is a world of change in which we live, and a world of uncertainty. We live only by knowing something about the future; while the problems of life or of conduct at least, arise from the fact that we know so little. This is as true of business as of other spheres of activity" [6].

Although Knight's framing of the central problem of business is as true today, as it was nearly a century ago, modern business endeavours have been aided by an important distinction made by Knight, between the concepts of risk and uncertainty.

In Knight's conception, the business environment includes both 'measurable uncertainty', which he terms as risk, and 'unmeasurable uncertainty', which he labels as uncertainty. Knight further clarifies this statement by stating that; "We can also employ the terms "objective" and "subjective" probability to designate the risk and uncertainty respectively" [6].

Thus, for Knight, risk is a situation with an objectively measured probability of occurrence (or very near objective, such as those probabilities found in the Insurance industry), while uncertainty is a situation that has only subjective probabilities of occurrence, and is hence not "'measured'. Knight suggests that the creation of subjective probabilities by an individual necessitates two separate exercises of judgment, the formation of an estimate and the estimation of its value [6]. In Knight's view, estimates of future events form a spectrum of sorts (see Figure \#1), between risk (objective estimates) and uncertainty (subjective estimates), where these estimates involve two dimensions:

a) The estimate of the occurrence of an event b) The estimate of impact of the event if it occurs

With this formulation of risk and uncertainty, Knight set the foundations for our modern risk paradigm [7, $8,9]$. His theorization has evolved in our modern use, where risk is widely understood as "...the effect of uncertainty on objectives... uncertainty is the state, even partial, of deficiency of information related to, understanding or knowledge of an event, its consequences or likelihood" [10].

In addition to setting the platform for the modern risk paradigm, Knight simultaneously laid the foundation for a body of research that has advanced in a number of important directions since then. One of these important directions is the idea of ambiguity discussed below.

\section{Figure 1. Diagram of the Risk \& Uncertainty Spectrum}

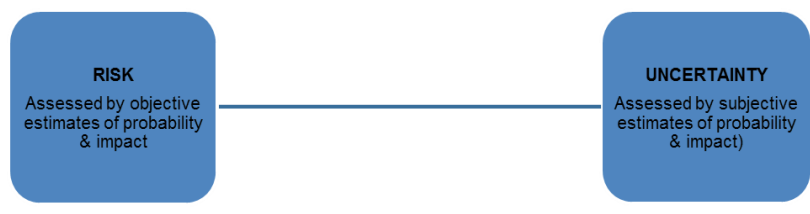

\subsection{Ambiguity}

One of the important advances in risk thought after Knight is the addition of the concept of ambiguity. Although many researchers have introduced the concept of ambiguity in one form or another $[11,12$, $13,14,15]$, the work of Ellsberg $[16]^{6}$ is of particular importance to the risk paradigm founded by Knight. Ellsberg contends that the nature of one's information concerning the relative likelihood of events is a third important factor in estimating future events [16]. Ellsberg states:

"What is at issue might be called the ambiguity of this information, a quality depending on the amount, type, reliability and 'unanimity' of information, and giving rise to one's degree of 'confidence' in an 
estimate of relative likelihoods" [16].

So in short, Ellsberg adds a third factor to the risk formula, where he adds 'confidence' to Knight's two factors of likelihood and impact. Where Knight suggests that subjective estimates of the impact and likelihood of future events are the crux of the uncertainty situation, Ellsberg suggests that our confidence in the knowledge that we use to determine our subjective estimates will vary, based upon the quality of the information available to our estimating faculties.

Bearing the preceding discussion of Knight and Ellsberg in mind, we can summarize that:

a) Risk is a situation where the probability and impact estimates of an event are objectively known, and the confidence in the quality of information used to construct these estimates is very high.

b) Uncertainty is a situation where the probability and impact estimates of an event are subjectively determined, and the confidence in the quality of information used to construct these estimates varies from low to high.

In short, risk is a very special-case of uncertainty, and uncertainty itself can potentially be reduced through better information ${ }^{7}$. In the next section of this work another important development will be investigated that has emerged to bolster and alter our modern conceptions of risk, that of Cognitive uncertainty.

\subsection{Cognitive Uncertainty}

The ideas that are here termed as Cognitive uncertainty are elsewhere known as 'The cognitive science perspective on risk' [9] or 'The managerial perspective on risk' [17]. Irrespective of the label that is used to describe this school of thought, this body of work serves to take aim at the foundations of rational decision theory in economics, and then seeks to show the limitations of rational decision theory in respect to its conceptions of risk $[17,18]$. Premised largely

\footnotetext{
${ }^{7}$ It's important to note that the engineering literature for one, distinguishes between epistemic and aleatory uncertainty: "... aleatory uncertainty, which arises because the system under study can behave in many different ways and is thus a property of the system, and epistemic uncertainty, which arises from a lack of knowledge about the system and is thus a property of the analysts performing the study. When a distinction between aleatory and
}

upon the famous body of psychological experiments undertaken by Daniel Kahneman and Amos Tversky [19, 20, 21], Cognitive uncertainty research has illustrated a series of choice problems, where people's preferences systematically violate 'rationality' [19]. Building upon these foundational psychological works, other researchers such as March and Shapira $[17,18]$ and Kunreuther et al [22], have worked to bring these findings squarely within the domain of Organizational theory.

In this work Cognitive uncertainty is defined as the subjective or inter-subjective perceptual and cognitive biases that influence exercises of judgment $[23,9,6]$. For example, March and Shapira [17] outline three important realities in organizational life, unaccounted for in decision theory that are some of the central concerns of Cognitive uncertainty; 1) Most managers do not treat uncertainty about positive outcomes as an important aspect of risk, 2) For most managers risk is not a probability concept, and 3) Most managers demonstrate little desire to reduce risk to a single quantifiable construct.

After highlighting these gaps in the traditional decision theory paradigm, March and Shapira [17], conclude by highlighting the empirical findings of Cognitive uncertainty:

a) Probability estimates by managers are treated as unreliable and are subject to post-decision control and revision, and considerations of trade-offs are framed by attention factors that considerably affect action.

b) Managers seek alternatives that can be managed to meet targets, rather than assess or accept risks.

c) The perspectives that managers have on risk are not simply matters of individual taste but are embedded in the social norms and expectations of the firm and the profession in general.

A few years later, March and Shapira [18] built upon these initial findings, by investigating the variability of risk preferences, noting how individual risk taking

epistemic uncertainty is not maintained, the deleterious events associated with a system, the likelihood of such events, and the confidence with which both likelihood and consequences can be estimated become commingled in a way that makes it difficult to draw useful insights" [48]. Thus, in this work the discussion is referring to epistemic uncertainty. 
behavior changes in relation to the changing fortunes of the manager and the organization. In this work, they highlight five focus-of-attention factors as critical to our understanding of the varying risk preferences and risk-taking behavior of individuals:

1. Risk taking and danger

2. Risk taking and slack

3. Risk taking in the neighborhood of an aspiration level

4. Risk taking and the assimilation of resources

5. Risk taking and self-confidence

Their first factor states that individual risk taking behavior is affected by threats to the survival of the organization, where increasing threats to survival stimulate greater and greater risk taking, presumably in an effort to escape the threats [18].

In the second factor, risk taking behavior appears to be affected by slack, that is, by resources in excess of current needs. In situations where slack is plentiful, slack is depicted as leading to a relaxation of controls, reduced fears of failure, institutionalized innovation, increased experimentation, and to relatively high levels of risk taking [18]. In situations where slack is small(or negative), tight controls and efforts to improve productivity using known technologies and procedures, is seen as producing relatively low levels of risk taking [18].

In the third factor, risk taking behavior appears to be affected by an aspiration-level reference point, which implies that when an individual orients to some target, and when they are close to said target, the individuals appear to be risk seeking below the target and risk averse above it [18].

The fourth factor details that risk-taking behavior seems to be sensitive to the risk takers perception of the resources being risked. It appears that greater risks are taken with new resources than with resources held for a longer time, and that managers appear to be more inclined to take risks with an organization's resources than with their own personal resources [18].

The fifth and final factor emphasizes the actuality that successful risk takers seem to feel that their past successes in risky situations are a result of their personal skills rather than their good fortune [18].

In short, Cognitive uncertainty research illustrates the day-to-day reality of risk decisions, risk preferences and risk behavior for managers and researchers everywhere. The research has illustrated that individuals in organizations generally do not follow 'risk recipes' such as those promoted in the ISO 2009 standard [10]. Furthermore, this research highlights that focus-of-attention factors exist, and that these factors serve to change both the perception of risk and the resulting risk-taking choices and actions of people in organizations.

Although projects are unique endeavors, we know that all projects take place within or between organizations, and area actuated by individuals and teams, which suggests that there is some significant overlap between project and organizational phenomena. Furthermore, although project managers and managers in organizations face different opportunities, constraints, and challenges in their work, both sets of practitioners have the need to continuously make decisions to guide their work, and the work of others. These traits, common to managers in all realms, suggest that the Cognitive uncertainty literature stemming from organizational research is very much relevant to project practitioners and project risk researchers, and in turn supports the application of it here.

In the ensuing section of this work, the PSPRM will be closely investigated to illustrate how the PMI suggests that Project Managers should undertake risk management in a project environment, which in turn will provide us a detailed look at the framework upon which many project risk management researchers base their research.

\section{The Practice Standard for Project Risk Management}

As previously mentioned, risk management, particularly in relation to budget and schedule overruns, is central to the literature on the management of projects [24]. Project risk management is considered by some to be so salient to projects, that it is suggested that project risk management process be treated "....as a project in its own right..." [25].

In this section the Practice Standard for Project Risk Management as offered by the PMBOK [26, 27] is closely investigated. In projects, risk is defined as "... an uncertain event or condition, that if it occurs, has a positive or a negative effect on a project's objectives... this definition includes two key dimensions of risk: uncertainty and effect on a project's objectives" [27]. The “...uncertainty dimension may be described using the term 
"probability" and the effect may be called

"impact"..." [27].

\subsection{Project Risk Management Process Flow- Step \#1 and \#2}

Figure \#2 below, illustrates the risk management process for project management ${ }^{8}$. As illustrated by the diagram, the first step in the PSPRM process is risk management planning. This step, defines the scope and objectives of the Project Risk Management process, and ensures that the risk process is fully integrated into the wider project management process [27]. Further, the objectives of this step in the process are to develop the overall risk management strategy for the project, and to decide how the risk management activities will be executed [27].

\section{Figure 2. The Project Risk Management Process Flow Diagram}

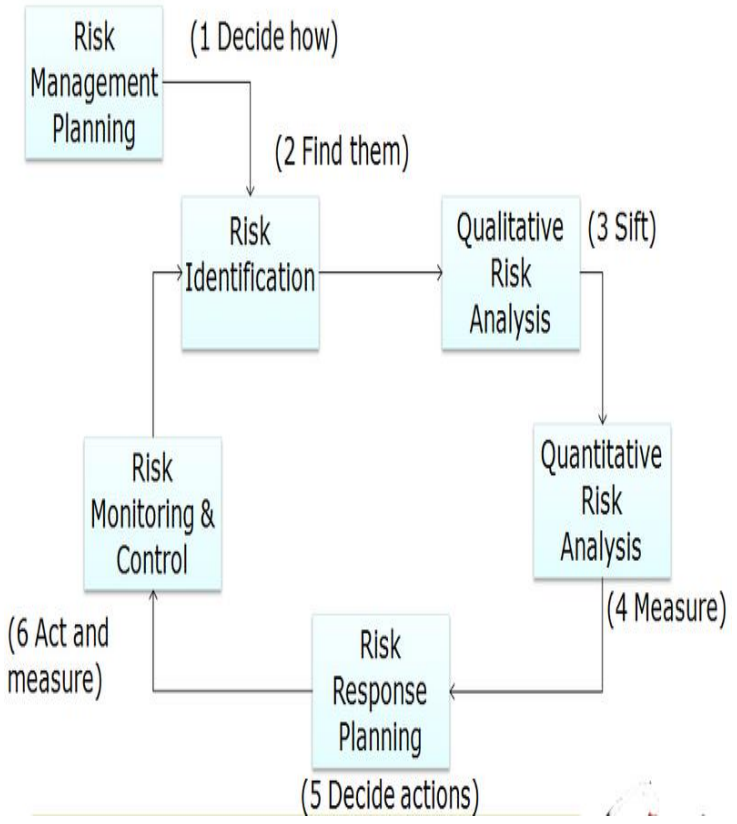

The PMI states that effective risk management requires the creation of a risk management plan that should define the normal frequency for repeating the processes, as well as specific or exceptional conditions under which the corresponding actions should be taken [27].

\footnotetext{
${ }^{8}$ This particular diagram is a rendering of the actual diagram found in [27] and is not completely identical to that of the PSPRM, but
}

In the second step of the project risk management process, the risk identification process states that " $\mathrm{A}$ risk cannot be managed unless it is first identified" [27], and that this step in the process aims to identify all the knowable risks to project objectives [27]. To identify risks adequately, the PMI suggests that risk identification should be performed as early as possible in the project lifecycle, while recognizing the paradox that uncertainty is high in the initial stages of a project, where there is often less information on which to base the risk identification [27]. To combat the lack of information at the beginning of a project, PMI suggests that risk identification should be; iterative, emergent, and comprehensive, explicitly identifying opportunities, including multiple perspectives in the formulation, and linking risks to project objectives [27].

This stage of the project risk management process results in the main output from the Identify Risks process, which is the risk register [27]. The risk register includes a properly structured risk description and the nominated risk owner for each risk, and may also include information on the causes and effects of the risk, trigger conditions, and preliminary responses [27]. Once the risk register is created, the identified risks in the register will undergo a qualitative and quantitative analysis in the next steps, providing an update to the initial risk register.

\subsection{Project Risk Management Process Flow- Step \#3 and \#4}

The third step in the PSPRM process is Qualitative risk analysis, which serves to assess and evaluate the characteristics of the identified project risks, and prioritizes risks using a subjectively determined probability that each risk will occur, and the predicted effect of each individual risk on project objectives [27]. This analysis may also include other factors as determined by taste, such as; urgency, manageability, and impact external to the project.

One step in this analysis is to categorize risks according to their sources or causes, to potentially determine a root cause, where the agreement of the project stakeholders is considered to be a fundamental criterion and a common theme of this step in the process [27]. This process can result in a 'Probability and Impact Matrix', which combines the estimated values for the probability and impact of an

the six steps in this process diagram, map exactly to the six steps listed PSPRM process diagram. 
event, and computes their relative importance by multiplying the values [26]. Although there is some relatively simple calculation involved in the qualitative process, it is classified as qualitative, since the values given for impact and probability are subjectively determined by the project manager and stakeholders.

On the other hand, the fourth step in the process, Quantitative risk analysis provides a numerical estimate of the overall effect of risk on the objectives of the project, based on current plans and information, when considering risks simultaneously [27]. This process can use techniques such as decision tree analysis, and modeling and simulation techniques such as Monte Carlo analysis, though it is recognized that quantitative risk analysis is not always required or appropriate for all projects [27].

This step in the PSPRM process also has its own complete sub-structure, captured in a process model including the following steps: 1] Examine interrelationships between risks 2] Collect high quality risk data 3] Project modelling 4] Perform quantitative analysis 5] Analyze the results [27].

\subsection{Project Risk Management Process Flow- Step \#5 and \#6}

The fifth step in the process, risk response, predetermines effective risk response actions in advance of a potential risk event occurring. The objective of the risk response plan is to pre-determine sets of actions which most enhance project success while complying with applicable organizational and project constraints. The planning involves agreeing upon the actions to be taken and the potential changes to budget, schedule, resources, and scope which these actions might cause [27].

The responsibility for monitoring the project conditions and implementing the corresponding action should be clearly assigned ahead of time, and each of the corresponding risk responses should be assigned to a specific risk action owner [27].

Furthermore, the project manager should develop risk response strategies for individual risks, sets of risks, and project level risks and such strategies include: 1) avoiding a threat or exploiting an opportunity 2) transferring a threat or sharing an opportunity 3)

\footnotetext{
${ }^{9} \mathrm{~A}$ risk that remains after risk responses have been implemented [27].
}

mitigating a threat or enhancing an opportunity 4) accepting a threat or an opportunity [27].

The sixth and final step in the PSPRM process is to monitor and control risks. In this step, the primary objectives are to track identified risks, monitor residual risks ${ }^{9}$, identify new risks, ensure that risk response plans are executed at the appropriate time, and evaluate their effectiveness throughout the project life cycle [27]. For each risk previously identified, for which a response has been crafted, and trigger conditions have been identified, it is the responsibility of the action owner to ensure that these conditions are effectively monitored and that the corresponding actions are carried out as defined, in a timely manner, should the risk occur [27].

With this in-depth review of the PSPRM process completed, in the ensuing section, the PSPRM is compared to the organizational risk literature to identify inconsistencies and to draw out implications for research and practice.

\section{Analysis \& Discussion}

When we compare the tenets and prescriptions of the PSPRM to the organizational risk literature reviewed here, a number of important facts emerge, which will be discussed in turn below.

\subsection{Risk, Uncertainty, and Ambiguity}

From the preceding review, we see that the fundamental ideas of risk as formulated by Knight have been implemented in the PSPRM, where risk is treated as a function of the probability of occurrence of an event, and the impact of the event if it occurs $[10,27]$. However, beyond the impact and probability facets of risk, the PSPRM displays some gaps in its use of the organizational risk literature. In this section, we highlight these gaps and suggest implications for practice and research.

First of all, in the PSPRM framework uncertainty is conceptualized as a dimension of risk itself (ie "risk is the effect of uncertainty on objectives"), and not as a separate category of phenomenon that can and does occur simultaneously with risk. Such categorization negates Knight's important distinction between risk and uncertainty altogether and further ignores Knight's important distinction between subjective and objective probabilities. If accurately applied in 
the PSPRM, project managers would be aware that risks and uncertainties likely co-exist in each and every project and that thus, what we now call "project risk management" is more accurately "project risk and uncertainty management". This difference is not solely semantic, given that risks are a readily identifiable special case of uncertainty, with very different attributes than uncertainties. Further, not all uncertainties themselves are equally uncertain, and so nuance is very much needed to distinguish among uncertainties.

Second, ambiguity as Ellsberg defined it, is completely absent from the PSPRM. The concept of ambiguity, if used as intended, should result in a third subjective estimate of uncertainty (in addition to probability and impact), namely the confidence that we have in the information upon which we are predicating our subjective estimates.

One area where these conceptual gaps may have an impact on practice is in the realm of Project Management education. The PSPRM is not only a "credentialing tool" for the PMI, but it is also, like PMBOK overall, an instrument of education for the entire profession and beyond. Thus, prospective project managers who are only just entering the field, and the project risk field specifically, are not being trained as comprehensively or with as much nuance as might be possible.

Third, if these fundamental concepts were treated accurately in the PSPRM, and thus followed in practice, then actual project risk management practice may become more effective. For example, since we now understand that uncertainty is a result of the subjective estimates of probability and impact, it may make sense to add a "confidence" element to a Probability and Impact Matrix. If this were to happen, the project manager may be more effective in prioritizing project risks and uncertainties, since she has a third dimension by which to distinguish and sequence the risks and uncertainties. Notwithstanding other changes, this simple act of adding a 'confidence' element to a Probability and Impact Matrix, should serve to make a project's risk register both more useful and more coherent. For example, we may now identify and distinguish between events with high impact, high probability, and low information confidence, as opposed to events with high impact, high probability, and high information

${ }^{10}$ Ward and Chapman [1] identify and classify five specific sources of uncertainty in projects: a] The variability associated with project parameters [ie time, scope, budget] b] The basis of estimates of project parameters c] Design and logistics d] Objectives and priorities d] Relationships between project parties. Their study confidence. Events identified as low confidence would seem to indicate gaps in our information, and thus areas where a project manager may need to dig deeper to firm-up and increase confidence levels. Nonetheless, if all project risk management were to improve through these very simple means, by a very small margin, say $1 \%$, the benefits for business and society would be tremendous.

For researchers relying on the PSPRM framework as a guide, defining risk as a function of uncertainty nullifies the manifest difference between objectively determined and subjectively determined estimates of probability and impact, and may lead to numerous definitions of risk [28]. Furthermore, an important implication of this discussion for researchers is that all subjective estimates of probability and impact are not created equal, but the confidence in the information upon which we predicate subjective estimates, is a readily identifiable factor, allowing us to differentiate between your subjective estimate and mine. Said another way, all subjective estimates of future events are not equally good, since our estimates are subject to a different quality and quantity of input information in each case. This leaves us in a situation with risk, which is approaching full information (since there's no such thing as perfect information or true certainty), and a range of differing uncertainties based upon relative information quality. In this sense, project risk management is really about the management of risk, uncertainty, and information confidence. Although others in the project risk literature have mentioned uncertainty management $[1]^{10}$ as far as this researcher is aware, none have outlined that project risk management may really be about the management of risk, uncertainty, and information confidence. This would seem to indicate that project risk research has nuance to discover and new avenues to falsify.

In the next section, we'll discuss another area where the PSPRM might be improved, with further examples of the potential bearing on practice and research.

\subsection{Absence of Cognitive Uncertainty}

We can see that the concepts of Cognitive uncertainty are not explicitly incorporated into the PSPRM framework (see Figure \#2). This fact is somewhat

approaches risk management from the perspective of the project life cycle, and they do not focus on any specific risk management framework or any specific stages found in risk management frameworks. Nonetheless, they do conclude that viewing project risk management as project uncertainty management is desirable. 
surprising given the prominence of the foundational work from Kahneman and Tversky [19, 21], which has spawned a new field of Economics known as Behavioral Economics [29, 30], and the fact that Daniel Kahneman has won the Nobel prize for his work in this area [31].

However, there are several hurdles that can explain this gap. First, the chasm between research and standards is wide and deep [32]. Second, the general tendency of standards to deal with more explicit than tacit knowledge practices [33]. Incorporating Cognitive uncertainty concepts may stray more into the realm of reflective practice than is comfortable for a practice standard. Nonetheless, this gap in the PSPRM has potentially important implications for project risk management, and so we'll discuss the findings of March and Shapira [17, 18] in light of the PSPRM framework reviewed here.

First, March and Shapira [17] point out that probability estimates are treated as unreliable by managers, are subject to post-decision control and revision, and considerations of trade-offs are framed by attention factors that considerably affect action. This particular finding may have a major bearing on project risk management, especially considering that trade-offs between time, cost, and scope are thought to be very common for Project Managers [34, 35]. Furthermore, this finding highlights that a frame of attention for project trade-offs is set very early on in the project, by the risk identification and risk prioritization activities. Therein, it is likely useful for the project manager to be cognizant that an initial frame has been set early in the project, and that said frame will bias their ensuing risk monitoring.

Further, in terms of project risk research, previous research [5] suggests that a software development impact statement (SoDIS) has been effectively implemented on multiple continents. It may very well be that the efficacy of this tool, as an expanded and ongoing form of risk analysis, lies in the fact that it serves to re-frame attention factors as the project progresses, thus affecting the actions taken in project trade-offs.

Second, March and Shapira [18] illustrate that individual risk preferences vary through time according to five specific focus-of-attention factors; risk taking and danger, risk taking and slack, risk taking in the neighborhood of an aspiration level, risk taking and the assimilation of resources, and risk taking and self-confidence [18]. Since every project involves individuals making decisions in some capacity, and most specifically the decisions taken by a project manager, these shifting and variable factors are likely to be very important to the decisions being made in the name of the project over time. It may be that attention factors, such as risk taking and danger (where greater risk is taken when closer to failure) may at least partially explain the well-documented escalation of commitment [36], and the large budget and schedule overruns in many projects $[37,38]$. In these contexts, it may be that project managers take greater risks as a project begins to show signs of failure, in an effort to escape survival threats [18]. Overall, the PSPRM and project researchers could benefit from an explicit consideration of how attention-factors and aspiration-level reference points frame the decisions being made in project risk management.

In general, these Cognitive factors are fairly subtle, but very powerful, because they influence pretty much every aspect of knowledge work by individuals. And thus for the PSPRM to ignore that such powerful human forces are at play, and to further ignore what the Cognitive uncertainty research has already learned about these forces, is a huge disservice to projects, and especially for new project managers.

However, it's important to note that projects are not the only culprit in this regard. Many of the same errors and omissions exist in the ISO 31000 [10] standard for organizational risk management, and in the recently developed ISO 21500 [39] standard for project management. In many ways (for example the risk register) the PSPRM is the most advanced treatment of risk that exists in the business world, but that does not mean that it cannot continue to improve.

For researchers, it may be that it is useful to consider these subtle but powerful Cognitive factors as an antecedent condition of project risk research, especially when investigating individual-level/project manager-level research [40].

\section{Limitations and Future Research}

This work has two major limitations that need to be acknowledged. The first applies to the use of the organizational risk literature in this work, and the second applies to the IS-focus of this outlet. In terms of the first limitation, the risk literature used in this work is very far from comprehensive, and indeed it was purposely selective to focus on works that are recognized as foundational works in the field $[7,8,9]$. Although many more works in the organizational risk literature were reviewed by the 
researcher than are mentioned here, as the literature review process ensued it was observed that the apparent gaps in the PSPRM were tied directly to an under-appreciation of, or fundamental misunderstanding of these important works, and so the review was limited to said works to illustrate these important gaps. Given that the PSPRM as a document is an objective form of data, the logic was that the fundamental or foundational issues in the guide could be readily verified by anyone with an interest (by looking at the literature referenced and the PSPRM guide itself), and further that these gaps should be corrected prior to moving onto more specific issues flowing from these foundations. It is hoped that the limited review provides a useful starting point in this regard, while at the same time illustrating existence proofs [41] of the argumentation. Further, it is hoped that the starting point provided here endows a useful platform for future research seeking to integrate other areas of organizational risk knowledge that are already wellestablished, into the IS risk literature, including such topics as risk communications and risk migration [23, 42].

In respect to the second limitation, the focus is solely on the PSPRM in relation to the organizational risk literature. Given that a PSPRM does not exist that focuses only on IS Projects, and that the PMBOK and its accompanying materials are used to train and credential IS project managers too, the focus, and the resulting analysis is of salient and material concern to the IS field. Although there is a body of literature distinguishing IS projects (or IT-Enabled change projects $^{11}$ ) from other types of projects, and which underscores that IS projects are unique in respect to other projects -in that IS projects consist solely of 'knowledge workers' [43] and are chiefly concerned with IS artefact development and/or implementationthe fact remains that all project managers trained through the PMI use only the PSPRM as their guiding source for risk management credentialing and training.

Furthermore, despite the fact that there is a relatively well-established body of literature on IS project and software development risk [4, 44, 5, 28, 45, 40, 46] new research in this area must also consider the fundamental analysis that is put forward here to insure the continuing rigor and relevance of their investigations, and we can look forward to future research that investigates risk, uncertainty and information confidence management in projects,

\footnotetext{
${ }^{11}$ Hereafter referred to as IT Projects, IT-Enabled change or transformation projects are those projects concerned with the "one-
}

Ellsbergian ambiguity in projects, and the potential efficacy of the probability/impact/confidence matrix on IS projects and IS project outcomes.

More generally, it should also be noted that in the statistics research there are different perspectives on probability itself, including the frequentist and Fisherian schools [50], and objective and subjective Bayesian approaches $[50,51,52]$, which can be applied differently by project managers and researchers to tackle some of the opportunities presented in this analysis.

\section{Conclusion}

This work has sought to investigate whether the Practice Standard for Project Risk Management faithfully incorporates the existing concepts of the organizational risk literature. To answer this query, the work has looked at the history of economic risk thought, with a focus on the foundational risk literature in the field of organizational theory. In doing so, this work has provided a foundational review of the organizational risk literature and has applied the results of this review to the PSPRM. In short, this work finds support for the notion that the PSPRM is lacking important and well-established risk concepts in its present conception, and is simultaneously misusing other fundamental concepts. This overall finding is supported by the following specific details:

a) The PSPRM does not distinguish between the two types of events that can impact a project - Risk and Uncertainty.

b) The PSPRM does not include the idea that confidence levels should be applied to the subjective estimates of impact and probability. It is suggested that the PMI add a "Confidence" dimension to the Probability and Impact Matrix.

c) The PSPRM does not explicitly incorporate findings from the Cognitive uncertainty literature into the process flow diagram, or any of the individual stages described in the PSPRM. It is suggested that a start could be made in this direction by adding a section to Chapter \#9 of the

off' development and or implementation of IS applications within or between organizations. See [47] for further detail. 
PSPRM guide (Stage \#6 in Figure \#2), entitled "Cognitive Uncertainty", and that said section could perhaps begin with something similar to the following:

"The risk preferences and risk-taking behaviors of individuals vary throughout the course of the project. In regard to risk and uncertainty monitoring and control, it is important that you are aware that these varying preferences and behaviors exist, and are shaped by the following five focus-of-attention factors..."

Overall, it is particularly important for the practitioner community to become aware of the existing gaps in the PSPRM. Seeing that the PSPRM is the major risk management tool, and the major learning resource for risk management in projects, many practicing project managers may be continuously affected by these conceptual shortcomings.

To combat this situation, the PMI could create and deliver special workshops/training/talks on the subject, perhaps at PMI chapters around the world. Once awareness of these factors spreads within the PMI community, best practices will likely emerge to combat specific Cognitive uncertainty situations. It's likely that some of these already exist, but that they are not widely disseminated [5].

Although project risk management is already a difficult task due to the unique characteristics and constraints of projects, some projects will immediately benefit from a consideration of the gaps pointed out here. For example, those working within a PMO environment, should (or at least could) have "better" information already available [for example from the "lessons learned" of past projects or past risk registers etc.) than those in non-program environments, which should serve to improve their subjective estimates of uncertainty situations once they become aware of the situation.

Furthermore, implementing some of the suggestions discussed here can allow project managers to make more nuanced distinctions of which uncertainties they should allocate their limited attention to. So, the uncertainty discussion gives them a tool to better allocate their scarce attention, whereas the cognitive components of this discussion are likely to alert them to avoidable "framing" factors that they were likely not previously aware of.
This work has not exhaustively drawn out every implication for projects resulting from the gaps in the PSPRM treatment of risk and risk management. What has been attempted is to illustrate that there is space for the PSPRM to be potentially improved in its treatment of risk, and that doing so is likely to have some benefits for all projects. It's likely that once the smart and savvy individuals at PMI become fully aware of the gaps in their framework, they will very readily generate other specific alterations to the PSPRM, which will be effective for project risk and uncertainty management.

For the research community, many of whom base their investigations on specific components of the PSPRM framework, knowledge of the gaps outlined here is similarly important. As we have seen in this work, the analysis has drawn-out new and exciting avenues for research, and we look forward to future research that explicitly turns its attention to the investigation of Ellsbergian ambiguity in the project risk domain. Further, future researchers are invited to investigate objective and subjective estimates of probability and impact separately, and in light of the confidence factors of these estimates predicated on information quality. And finally, future project risk researchers are invited to consider the Cognitive uncertainty factors outlined here as an antecedent condition of research investigating individuallevel/project manager-level risk research.

\section{References}

[1] Ward, S.C., and C. Chapman (2003) "Transforming Project Risk Management into Project Uncertainty Management", International Journal of Project Management, 21(2), pp. 97-105.

[2] Maytorena, E., G.M., Winch, J., Freeman, and T. Kiely (2007) "The Influence of Experience and Information Search Styles on Project Risk Identification Performance", IEEE Transactions on Engineering Management, 54(2), pp. 315-326.

[3] Winch, G. M., and E. Maytorena (2009) "Making Good Sense: Assessing the Quality of Risky Decision-Making”, Organization Studies, 30(2-3), pp.181-203.

[4] Fenz, S., A., Ekelhart, and T. Neubauer (2011) "Information Security Risk Management: In which Security Solutions is it Worth Investing?

"Communications of the AIS" 28(1), pp. 5. 
[5] Gotterbarn, D., and S. Rogerson (2005)

"Responsible Risk Analysis for Software

Development: Creating the Software Development Impact Statement", Communications of the AIS, 15, pp. 750.

[6] Knight, F. (1921). Risk, Uncertainty and Profit. Boston: Houghton Mifflin Company.

[7] Fellner, W. (1961) "Distortion of Subjective Probabilities as a Reaction to Uncertainty", The Quarterly Journal of Economics, 75[4], pp. 670-689.

[8] Langlois, R. N., and M.M. Cosgel (1993) "Frank Knight on Risk, Uncertainty, and the Firm: A New Interpretation", Economic Inquiry, 31(3), pp. 456465.

[9] Gephart Jr., R.P., J., Van Maanen, and T. Oberlechner (2009) "Organizations and Risk in late Modernity”, Organization Studies, 30(2-3), pp. 141155.

[10] ISO 31000 (2009) Risk Management: Principles and Guidelines. International Organization for Standardization.

[11] March, J.G. (1978) "Bounded Rationality, Ambiguity, and the Engineering of Choice", Bell Journal of Economics, 9(2), pp. 587-608.

[12] Hogarth, R. M., and H. Kunreuther (1989) "Risk, Ambiguity, and Insurance", Journal of Risk and Uncertainty, 2(1), pp. 5-35.

[13] Alvesson, M. (1993) "Organizations as Rhetoric: Knowledge-intensive Firms and the Struggle with Ambiguity", Journal of Management Studies, 30(6), pp. 997-1021.

[14] Schrader, S., W. M., Riggs, and R. P., Smith (1993) "Choice Over Uncertainty and Ambiguity in Technical Problem Solving”, Journal of Engineering and Technology Management, 10(1), pp. 73-99.

[15] Pich, M.T., C.H., Loch, A., De Meyer (2002) "On Uncertainty, Ambiguity, and Complexity in Project Management", Management Science, 48(8), pp.1008-1023.

[16] Ellsberg, D. (1961) "Risk, Ambiguity and the Savage Axioms", The Quarterly Journal of Economics, 75[4], 643-669.
[17] March, J. G., and Z. Shapira (1987) "Managerial Perspectives on Risk and Risk Taking", Management Science, 33(11), pp. $1404-1418$.

[18] March, J. G., and Z. Shapira (1992) "Variable Risk Preferences and the Focus of Attention", Psychological Review, 99(1), pp. 172-183.

[19] Kahneman, D., and A. Tversky (1979) "Prospect Theory: An Analysis of Decision Under Risk", Econometrica, 47(2), pp. 263-291.

[20] Tversky, A., and D. Kahneman (1982) "Causal Schemas in Judgment Under Uncertainty", In Daniel Kahneman, Paul Slovic and Amos Tversky [Eds.], Judgment Under Uncertainty: Heuristics and Biases, Cambridge University Press, New York, pp. 117-128.

[21] Kahneman, D., and A. Tversky (1982) "Variants of Uncertainty", Cognition, 11(2), pp. 143-157.

[22] Kunreuther H., R., Meyer and E., Michel-Kerjan (2010) "Overcoming Decision Biases to Reduce Losses from Natural Catastrophe", In: Shafir E [ed] Behavioral Foundations of Policy, Princeton University Press.

[23] Greenberg, M., C., Haas, A., Cox, Jr., K., Lowrie, K., McComas, and W. North (2012) "Ten Most Important Accomplishments in Risk Analysis 1980-2010”, Risk Analysis, 32(5), pp. 771-781.

[24] Gil, N., and B. S. Tether (2011) "Project Risk Management and Design Flexibility: Analysing a Case and Conditions of Complementarity. Research Policy, 40(3), pp. 415-428.

[25] Chapman, C. (1997) "Project Risk Analysis and Management--PRAM the Generic Process", International Journal of Project Management, 15(5), pp. 273-281.

[26] Project Management Institute. (2008) A Guide to the Project Management Body of Knowledge [PMBOK ${ }^{\circledR}$ Guide], Newtown Square, Pa: Project Management Institute, 4th ed.

[27] Project Management Institute. [2009]. Practice Standard for Project Risk Management, Newtown Square, Pa: Project Management Institute.

[28] Alter, S., and S. Sherer (2004) "A General, but Readily Adaptable Model of Information System Risk", Communications of the AIS, 14(1), pp.1-28. 
[29] Ariely, D., and G. Loewenstein (2000) "When Does Duration Matter in Judgment and Decision Making?", Journal of Experimental Psychology: General, 129(4), pp. 508-23.

[30] Kahneman, D. (2003) "Maps of Bounded Rationality: Psychology for Behavioral Economics. The American Economic Review, 93[5), pp. 14491475.

[31] Kahneman D. (2002) "Nobel Prize Lecture: Maps of Bounded Rationality: A Perspective on Intuitive Judgment and Choice", In Nobel Prizes 2002: Nobel Prizes, Presentations, Biographies, and Lectures, ed. T Frangsmyr, Stockholm: Almqvist and Wiksell International, pp. 416-99.

[32] Maylor, H., et al. (2011) Research Informed Standards: Academic Research Input into the Project Management Institute Standards Program. Newtown Square, Pa: Project Management Institute.

[33] Reich, B. H., and S. Y., Wee (2006) "Searching for Knowledge in the PMBOK ${ }^{\circledR}$ Guide", Project Management Journal, 37(2), pp. 11-27.

[34] Vanhoucke, M., E.L., Demeulemeester, and W.S. Herroelen (2002) "Discrete Time/Cost Tradeoffs in Project Scheduling with Time-switch Constraints", Journal of the Operational Research Society, 53(7), pp. 741-751.

[35] MacCormack, A., C.F., Kemerer, M., Cusumano, and B. Crandall (2003) "Trade-offs Between Productivity and Quality in Selecting Software Development Practices", Software, 20(5), pp. 78-85.

[36] Jani, A. (2011) "Escalation of Commitment in Troubled IT projects: Influence of Project Risk Factors and Self-Efficacy on the Perception of Risk and the Commitment to a Failing Project", International Journal of Project Management, 29(7), pp. 934-945.

[37] Standish Group International (2001) "Extreme CHAOS", Retrieved 12/25/13 from http://blog.standishgroup.com/pmresearch

[38] Standish Group International (2011) "CHAOS Manifesto", Retrieved 12/25/13 from http://blog.standishgroup.com/pmresearch
[39] ISO 21500 (2012) Guidance on Project Management. International Organization for Standardization.

[40] Schmidt, R., K., Lyytinen, M., Keil, and P. Cule (2001)"Identifying Software Project Risks: An international Delphi Study", Journal of Management Information Systems, 17(4), pp. 5-36.

[41] Lucas, S.R. (2012) "Beyond the Existence Proof: Ontological Conditions, Epistemological Implications, and In-depth Interview Research", Quality \& Quantity, pp. 1-22.

[42] Alcock, R.E., and J. Busby (2006) "Risk Migration and Scientific Advance: The Case of Flame-Retardant Compounds", Risk Analysis, 26(2), pp. 369-381.

[43] Anne Keegan and J. Rodney Turner Quantity versus Quality in Project-Based Learning Practices Management Learning March 2001 32: 77-

98, doi:10.1177/1350507601321006

[44] Beebe, N.L., and V.S. Rao (2010) "Improving Organizational Information Security Strategy via Meso-level Application of Situational Crime Prevention to the Risk Management Process", Communications of the AIS, 26(1), pp.17.

[45] Sherer, S.A., and S. Alter (2004) "Information System Risks and Risk Factors: Are they Mostly About Information Systems", Communications of the AIS, 14(2), pp. 29-64.

[46] Barki, H., S., Rivard, and J. Talbot (1993) "Towards an Assessment of Software Development Risk", Journal of Management Information Systems, 10(2), pp. 203-225.

[47] Benjamin, R.I., and E. Levinson. (1993) "A Framework for Managing IT-enabled Change", Sloan Management Review, 34(4), pp. 23-33.

[48] Helton, J.C., and D.E. Burmaster (1996) "Guest Editorial: Treatment of Aleatory and Epistemic Uncertainty in Performance Assessments for Complex Systems", Reliability Engineering \& System Safety 54(2), pp. 91-94.

[49] Segal, U. (1987) "The Ellsberg Paradox and Risk Aversion: An Anticipated Utility Approach", International Economic Review, 28(1), pp. 175-202. 
[50] Berger, James. The case for objective Bayesian analysis. Bayesian Anal. 1 (2006), no. 3, 385--

402. doi:10.1214/06-BA115.

[51] Glickman, M. E., \& van Dyk, D. A. (2007). Basic Bayesian Methods. In Ambrosius, Walter, T., eds. Topics in Biostatistics: 404 Methods in Molecular Biology ${ }^{\mathrm{TM}}$, Humana Press. pp. 319-338. http://dx.doi.org/10.1007/978-1-59745-530-5_16

[52] Goldstein, Michael. Subjective Bayesian Analysis: Principles and Practice. Bayesian Anal. 1 (2006), no. 3, 403--420. doi:10.1214/06-BA116. 